\title{
Vertical vehicle displacement based drive-by inspection of bridge damage with parameter optimization
}

\author{
Yifu Lan \\ School of Civil and Environmental Engineering, University of New South Wales, Sydney NSW 2052, Australia \\ Corresponding Author : Elvislannnnnn@gmail.com
}

Submitted : 18/03/2020

Revised : 16/11/2020

Accepted :26/11/2020

\begin{abstract}
Recently, there has been an increasing emphasis on the Indirect bridge health monitoring method employing passing vehicles, which is regarded as one of the most effective approaches in bridge damage screening. However, few researches have been conducted on the drive-by bridge inspection method using vehicle displacement profile as damage indicator. This paper proposes a new drive-by inspection method based on vertical vehicle displacement profile with parameter optimization. A generalized Vehicle-Bridge Interaction (VBI) system is built in MATLAB, where the bridge is modelled as a simply supported beam with 10 elements, and the passing vehicle is represented as a simplified quarter car. To improve the result sensitivity to bridge damage, the parameter optimization of vehicle configuration is processed employing the Monte Carlo methods. Results show that the proposed method can successfully detect and localize bridge damage by using vertical vehicle displacement profile as damage indicator only, and its performance may depend on the vehicle configuration. The proposed approach provides merits in simplicity and efficiency, which can be applied widely to the bridge damage detection problems.
\end{abstract}

Keywords: Drive-by bridge inspection; Vehicle bridge interaction; Vertical vehicle displacement; Vehicle configuration; Parameter optimization.

\section{INTRODUCTION}

Bridges are the key components of transport infrastructure, however, bridges these days are experiencing challenges including not only the increasing traffic loads but also the gradual deterioration over time. More than $11 \%$ of bridges are structurally deficient in the United States and in Europe, most bridges were constructed from 1945 to 1965 (Malekjafarian et al. 2015). To guarantee the structural integrity and reliability of bridges, it is necessary to detect and localize the damage in the early stage. Effective application of SHM techniques can significantly reduce the maintenance cost and extend the structural life. Traditionally, the conventional SHM known as the "sensor-base monitoring" is employed to screen structural damage requiring numerous sensors attached to the bridge and its performance highly depends on the sensor's location and sensitivity (Sohn et al. 2003). For many years, the conventional SHM has been regarded as an expensive approach of damage inspection, where the sensor installation is always challenging and costly, especially for a bridge under ongoing traffic (Enckell et al. 2011). Noting that sensitive sensors will also be sensitive to environmental noises, the impacts of ongoing traffic and the environment 
in this regard are nonnegligible, which might mask the structural flaws resulting in low detection accuracy (Sohn et al. 2003). An alternative technique in bridge damage inspection is therefore highly demanded without instrumenting the bridge.

The Indirect SHM method employing the passing vehicle, which is regarded as one of the most effective approaches in bridge damage detection, is proposed by Yang et al. (2004). The basic concept of it is simple, which employs the vehicle as 'moving sensor' to obtain the dynamic properties of bridge via the Vehicle-Bridge Interaction (VBI). Instead of employing numerous instrumentations placed on the bridge, this approach uses a vehicle instrumented with the sensor, considering as both exciter and receiver. The bridge vibrates as the vehicle passing through it and the dynamic properties of bridge will be reflected in vehicle response via the VBI. Lin and Yang (2005) have experimentally examined the drive-by inspection method and the results show that the fundamental frequency of bridge can be successfully extracted by acceleration signals collected from the cart sensor placed on the suspension system, which aims at eliminating the noise from the vehicle engine. Structural damage will lead to changes in bridge dynamic properties, and practicably by tracking the vehicle responses the frequency changes due to damage can be extracted (Kim and Kawatani 2009). Compared with the conventional SHM methods, arguably advantages of the drive-by SHM method can be seen in economy, simplicity, feasibility and high resolution (Malekjafarian et al. 2015).

Based on diverse damage indicators, there are generally three approaches of bridge damage inspection employing passing vehicles. The first is based on the bridge damping ratio, in which the structural damage is represented as the increase in bridge damping ratio. It is found that the damping ratio increases will lead to changes in the acceleration spectra, and by tracking these changes the damage can be detected and localized (McGetrick et al. 2009). To reduce the noises from road profile, a strategy is by subtracting axle accelerations, in which the fast Fourier transform (FFT) is applied for the signal processing (Keenahan et al. 2014). The second is known as the mode shapebased damage inspection method, regarding the mode shape discontinuities as damage representor. Zhang et al. (2012) find that the point impedance can be obtained using the vehicle response when a specialized theoretical vehicle is employed to control the applied force on the bridge, and the amplitude of the point impedance spectra is proportional to the square of the mode shapes. Moreover, an algorithm introduced by Yang et al. (2014) shows that the instantaneous amplitude for the extracted bridge component response of specific mode is equal to the mode shape, which provides high-resolution results. The effects of road roughness can be effectively eliminated by increasing ongoing traffic loads and by subtracting axle accelerations (Malekjafarian and Obrien 2014).

In addition to the approaches introduced above, there is a trend of using displacement profile to detect the structural damage. Traditionally, the bridge deflection shape is always considered as damage representor, where the peak occurred in the displacement profile difference between healthy and damaged bridges could indicate the existence of damage. Its effectiveness has been examined by many researches and one is conducted by Miyamoto and Yabe (2012), who employ a city bus with accelerometers placed on rear axles to process the Drive-by inspection. In the research, the Wave integrals and the Fourier transform are used to acquire the bridge deflection shape, while the noise influence is eliminated by averaging different readings for the same bridge. OBrien and Keenahan (2015) propose a drive-by inspection method based on the apparent profile, which is the sum of road profile and bridge displacement history. The main challenge of it lies in the extraction of true damage profile, where the Cross Entropy (De Boer et al. 2005) optimization and Monte Carlo simulation are required. By subtracting the road profile, the bridge displacement profile difference can be solved to screen the structural damage.

With the recent development of deflectometer techniques, the role of Drive-by inspection using displacement profile as damage indicator has been increasingly emphasized. The Rolling Weight Deflectometer (RWD), which is initially proposed by Briggs et al. (2000) in the United States, has been recently developed for the Drive-by inspections specifically aiming at providing deflection profile with higher accuracy. Moreover, the introduction of "Traffic Speed Deflectometer" (TSD), a specialized device for vehicle capable of performing deflection surveys at 
speeds of up to $80 \mathrm{~km} / \mathrm{h}$, allows clear deflection profiles to be obtained showing high sensitivity to small damage and competitive accuracy in damage measurement (OBrien and Keenahan 2015). Arguably, the Drive-by inspection using displacement profile as indicator present advantages in simplicity and visualization, where the potential damage can be localized and quantified easily by displacement profile only. As the techniques of deflectometer developing rapidly, less challenges will be seen in the adoption of displacement profile and predictably the Drive-by inspection based on deflection profile will become increasingly popular.

However, few studies have been conducted on the Drive-by inspection methods using vehicle deflection as damage indicator. This is because traditionally the measurement of relative vertical vehicle displacement is challenging employing the conventional measuring approaches, especially when the damage is less significant (Yin and Tang 2011). Additionally, the vehicle dynamics could mask the damage characteristics even the highly sensitive sensors are available (Hester and González 2016). An attempt to identify bridge damage using vertical vehicle displacement is conducted by Yin and Tang (2011), who try to detect the cable loss and bridge damage by using vertical vehicle response only. Their research successfully verifies the effectiveness of Drive-by inspection based on vehicle displacement under specific vehicle configuration while the road profile impact is ignored. In fact, the vehicle configuration might vary and poor vehicle properties might lead to inaccurate measurement of damage. A parametric study focusing on the parameter effects is conducted by McGetrick and Kim (2013), illustrating that the vehicle response will be considerably affected by its configuration parameters involving vehicle stiffness, mass and damping. The appropriate vehicle configuration is therefore necessary for the Drive-by inspection methods using vertical vehicle displacement as damage indicator, and a practical strategy is by investigating the parameter effects and designing the optimum vehicle parameters before inspections.

This paper proposes a new method of Drive-by inspection with parameter optimization, which employs the vertical vehicle displacement profile as damage indicator. A generalized VBI system is established in MATLAB with a simply supported beam consisting of 10 elements and the passing vehicle is modelled as a quarter car model. Firstly, the effectiveness of vehicle displacement-based Drive-by inspection will be roughly examined using 4 groups of testing vehicle configurations. Secondly, the parametric investigation and optimization will be processed to determine the vehicle parameters that provide the preferable performance in terms of relative displacement measurement and result accuracy by the Monte Carlo methods. Thirdly, employing the optimum parameters acquired above, the performance of presented approach will be tested for different bridge spans under diverse damage scenarios. The effectiveness of parameter optimization in improving the result performance will be examined using a random configuration test. Compared with the conventional Drive-by inspection methods based on indicators like damping ratio and mode shape, this approach can provide advantages in simplicity and efficiency, and be applied widely to the bridge damage detection problems.

\section{VEHICLE-BRIDGE INTERACTION MODELING}

The bridge can be simulated employing the Finite Element Method (FEM), where the damage severity and location are represented as stiffness reduction level and the specific element, in which the stiffness loss occurs, respectively. It consists of discretized beam elements with 2 degrees of freedom (DOF) per node, vertical translation and rotation. Bridge properties such as mass per unit length, $\mu$, modulus of elasticity $E$ and second moment of area $J$ are constant. As recommended by Lin and Yang (2005), a vehicle model should involve parameters of $\mathrm{m}_{\mathrm{v}}$ (vehicle mass), $\mathrm{k}_{\mathrm{v}}$ (vehicle stiffness) and $\mathrm{c}_{\mathrm{v}}$ (vehicle damping), regarding the exciter to the bridge. The vehicle could therefore be represented as a quarter car model, travelling at constant speed $\mathrm{v}$ over the bridge, where the model can generally present the primary characteristics of vehicle (Cebon 1999). The road profile for the model is defined as "Class A" representing "Very good" roughness condition (ISO 8608:1995). The VBI model is illustrated in Figure 1. 


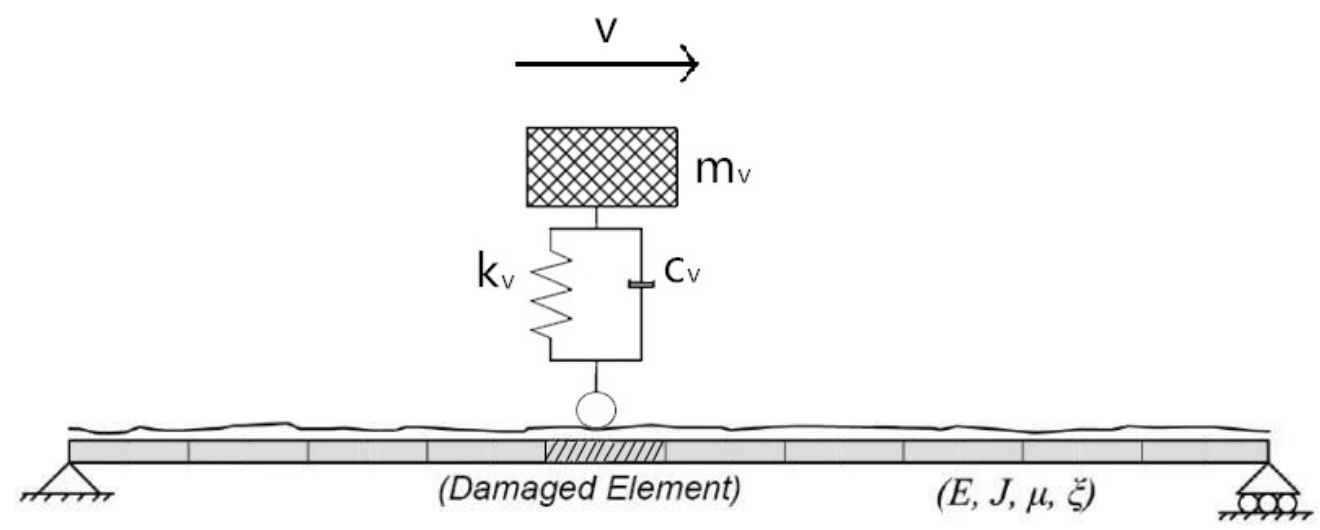

Figure 1. VBI Model.

The VBI progress is solved using the contact force concept reported by Gonza'lez (2010), in which the vehicle and bridge equations of motion are solved separately then equating the contact forces between vehicle and bridge at each time step i:

$$
\begin{aligned}
& {\left[\mathrm{m}_{\mathrm{v}}\right]\left\{\ddot{y}_{\mathrm{v}}\right\}_{\mathrm{i}}+\left[\mathrm{c}_{\mathrm{v}}\right]\left\{\dot{y}_{\mathrm{v}}\right\}_{\mathrm{i}}+\left[\mathrm{k}_{\mathrm{v}}\right]\left\{\mathrm{y}_{\mathrm{v}}\right\}_{\mathrm{i}}=\left\{\mathrm{f}_{\mathrm{v}}\right\}_{\mathrm{i}}} \\
& {\left[\mathrm{m}_{\mathrm{b}}\right]\left\{\ddot{y}_{\mathrm{b}}\right\}_{\mathrm{i}}+\left[\mathrm{c}_{\mathrm{b}}\right]\left\{\dot{y}_{\mathrm{b}}\right\}_{\mathrm{i}}+\left[\mathrm{k}_{\mathrm{b}}\right]\left\{\mathrm{y}_{\mathrm{b}}\right\}_{\mathrm{i}}=\left\{\mathrm{f}_{\mathrm{b}}\right\}_{\mathrm{i}}}
\end{aligned}
$$

In the equations, $\left[\mathrm{m}_{\mathrm{v}}\right],\left[\mathrm{c}_{\mathrm{v}}\right]$ and $\left[\mathrm{k}_{\mathrm{v}}\right]$ represent mass, damping and stiffness matrices of the vehicle respectively while $\left\{\ddot{y}_{\mathrm{v}}\right\},\left\{\dot{y}_{\mathrm{v}}\right\}$ and $\left\{\mathrm{y}_{\mathrm{v}}\right\}$ are the acceleration, velocity and displacement vectors of vehicle respectively. Likewise, the items $\left[\mathrm{m}_{\mathrm{b}}\right],\left[\mathrm{c}_{\mathrm{b}}\right]$ and $\left[\mathrm{k}_{\mathrm{b}}\right]$ are mass, damping and stiffness matrices for bridge respectively. The $\left\{\ddot{y}_{\mathrm{b}}\right\},\left\{\dot{y}_{\mathrm{b}}\right\}$ and $\left\{\mathrm{y}_{\mathrm{b}}\right\}$ are bridge acceleration, velocity and displacement vectors respectively. The non-zero components of the vector, $\left\{\mathrm{f}_{\mathrm{v}}\right\}_{\mathrm{i}}$ represent the dynamic interaction forces:

$$
\mathrm{f}_{\mathrm{vci}}=\left(\mathrm{w}_{\mathrm{bi}}+\mathrm{r}_{\mathrm{i}}\right) \mathrm{k}_{\mathrm{s}}
$$

where $\mathrm{k}_{\mathrm{s}}$ is the suspension stiffness and $\mathrm{w}_{\mathrm{bi}}$ is the deflection of bridge, while in the equation, $\mathrm{r}_{\mathrm{i}}$ represents the road profile height. and $\left\{\mathrm{f}_{\mathrm{b}}\right\}_{\mathrm{i}}$ is the applied force vector on the bridge, which is given as

$$
\left\{\mathrm{f}_{\mathrm{b}}\right\}_{\mathrm{i}}=\left(\mathrm{w}-\left[\mathrm{m}_{\mathrm{v}}\right]\left\{\ddot{y}_{\mathrm{v}}\right\}_{\mathrm{i}}\right) *\left\{\mathrm{~N}_{\mathrm{b}}\right\}_{\mathrm{i}}
$$

where $\mathrm{w}$ is the vehicle gravity weight and $\left\{\mathrm{N}_{\mathrm{b}}\right\}_{\mathrm{i}}$ is the location function that assigns the interaction force to the element degrees of freedom at the $i$ th step.

The vehicle response is solved through an iterative process, in which the bridge deflection under vehicle is calculated until the increment in bridge deflection is less than a specific percentage (Clough and Penzien 1975). It is firstly assumed that no deflection is occurred on the bridge at the beginning and the vehicle contact force is solved for the whole simulation employing Eq. 3. Secondly, by solving the Eq. 1 using Newmark-beta integration scheme the vehicle response can be calculated. Thirdly, the vehicle accelerations obtained are used in Eq. 4 to calculate the applied force on the bridge, after which the bridge deflection vector is calculated by Newmark-beta integration scheme. Lastly, the bridge displacements, $\mathrm{w}_{\mathrm{bi}}$ are computed as 


$$
\mathrm{w}_{\mathrm{bi}}=\left\{\mathrm{y}_{\mathrm{b}}\right\}_{\mathrm{i}}^{\mathrm{T}}\left\{\mathrm{N}_{\mathrm{b}}\right\}_{\mathrm{i}}
$$

The process will be proceeded repeatedly using the new $\mathrm{w}_{\mathrm{bi}}$ until less than $1 \%$ is witnessed in the ratio between the max bridge displacements in the old and new profiles. The vector $\left\{\mathrm{y}_{\mathrm{v}}\right\}$ is obtained by repeating the same process in the simulation, which is the vehicle displacement corresponding to each time step. Figure 2 shows the proposed VBI algorithm:

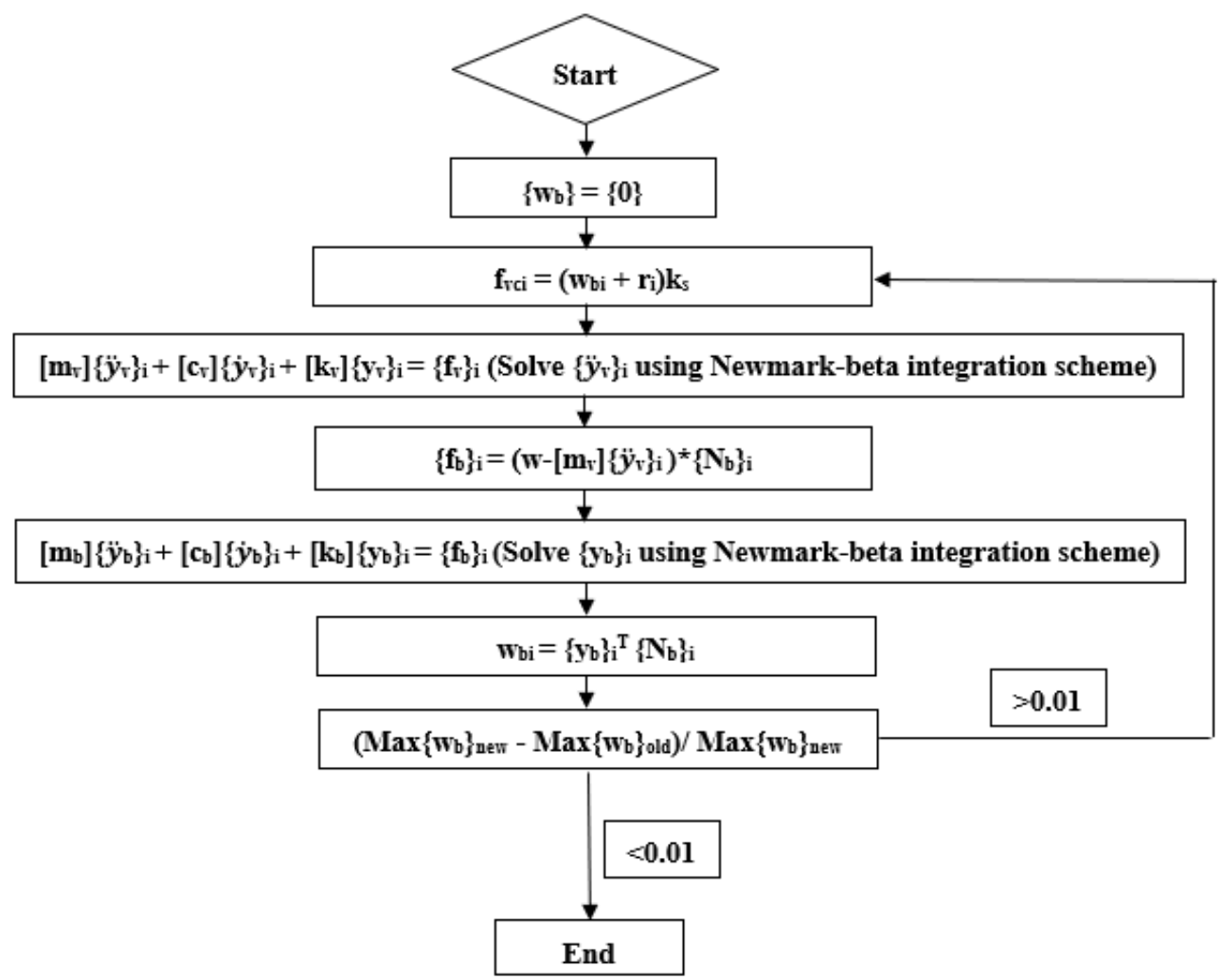

Figure 2. VBI algorithm.

\section{DAMAGE DETECTION USING VEHICLE DISPLACEMENT PROFILE}

In this section, the vertical vehicle displacement is used as damage indicator for the bridge health monitoring. The bridge span is chosen as $25 \mathrm{~m}$ with constant properties as described in Table 1. According to Sinha et al. (2002), the bridge damage can be identified as loss in stiffness due to structural defects like cracks. The damage location is described as the specific element in which the damage occurs while the damage severity (level) is presented as $\mathrm{x} \%$ stiffness reduction in the element. Bridge damage in this study is included in element 2, 6 and 8 with damage levels increasing from $10 \%$ to $80 \%$ gradually. The present damage in this section will be inspected employing 4 groups of vehicle configurations as shown in Table 2, where zeta is the vehicle damping ratio $\left(\right.$ zeta $\left.=\frac{c_{v}}{2 \sqrt{k_{v} m_{v}}}\right)$. Through the VBI simulations, the vehicle time histories based on diverse damage scenarios can be adopted employing testing vehicle configurations below. Figure 3-5, the Vehicle displacement difference profiles, are obtained based on the 
differences between vehicle time histories of damaged beams and the baseline, where the baseline is acquired using the vehicle deflection profile of healthy beam.

Observably, the position and magnitude of peak differ as the vehicle parameters vary even for the same damage situation. For example, the peaks occur at just before $15 \mathrm{~s}$ in Figure 4, while the accurate position should be at $15 \mathrm{~s}$ $(60 \%$ of the total time period) indicating the damage existed in Element $6(60 \% \mathrm{~L})$. Similar trends can be seen in Figure $3 \& 5$, with damage presented in Element 2 and 8, showing that the peaks do not indicate the damage locations exactly. It can be also seen that even for the same damage location, the displacement difference changes significantly with different vehicle configurations, but the relative displacement difference between two damage levels stay constant. Accordingly, the vehicle parameters such as vehicle stiffness and mass play key roles in the damage inspection performance based on vehicle displacement profile. A feasible strategy to improve the detection performance could be by designing the vehicle configuration, aiming at developing its accuracy and sensitivity to damage.

Table 1. Bridge Properties.

\begin{tabular}{|c|c|c|c|c|}
\hline $\begin{array}{c}\text { Span } \\
(\mathrm{m})\end{array}$ & Natural frequency $(\mathrm{Rad} / \mathrm{s})$ & Sectional area $\left(\mathrm{m}^{2}\right)$ & $\begin{array}{c}\text { Intact } \\
\text { element }\end{array}$ & $\begin{array}{c}\text { Mass per unit length } \\
(\mathrm{kg} / \mathrm{m})\end{array}$ \\
\hline 20 & 2 & 2.0 & $3.3 \times 10^{9}$ & 4800 \\
\hline 25 & 2 & 2.0 & $3.3 \times 10^{9}$ & 4800 \\
\hline 30 & 2 & 2.0 & $3.3 \times 10^{9}$ & 4800 \\
\hline
\end{tabular}

Table 2. Vehicle Properties.

\begin{tabular}{|c|c|c|c|c|}
\hline & zeta & $\mathrm{k}_{\mathrm{v}}(\mathrm{N} / \mathrm{m})$ & $\mathrm{m}_{\mathrm{v}}(\mathrm{kg})$ & $\mathrm{v}(\mathrm{m} / \mathrm{s})$ \\
\hline Vehicle 1 & 0.200 & 25000.0 & 5000.0 & 1 \\
\hline Vehicle 2 & 0.150 & 50000.0 & 10000.0 & 1 \\
\hline Vehicle 3 & 0.100 & 75000.0 & 15000.0 & 1 \\
\hline Vehicle 4 & 0.050 & 100000.0 & 20000.0 & 1 \\
\hline
\end{tabular}




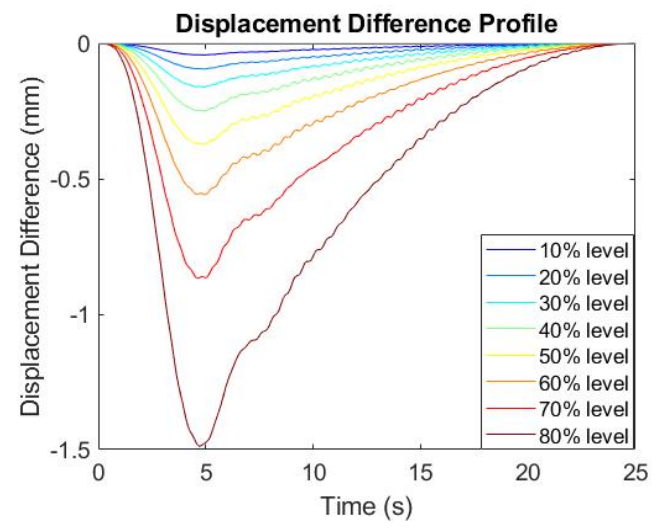

(a)

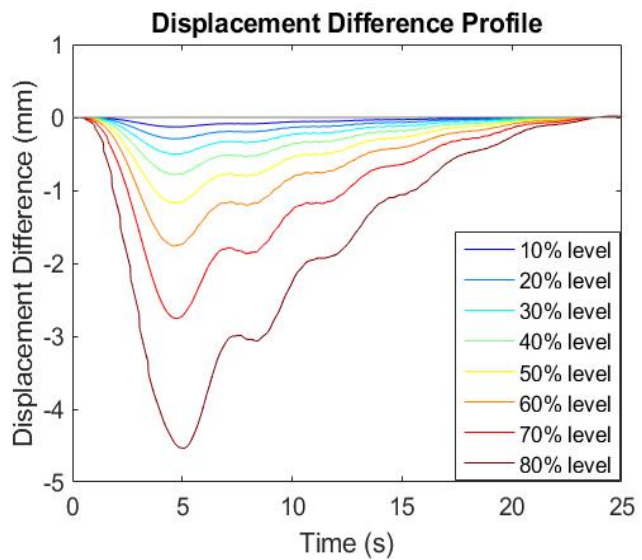

(c)

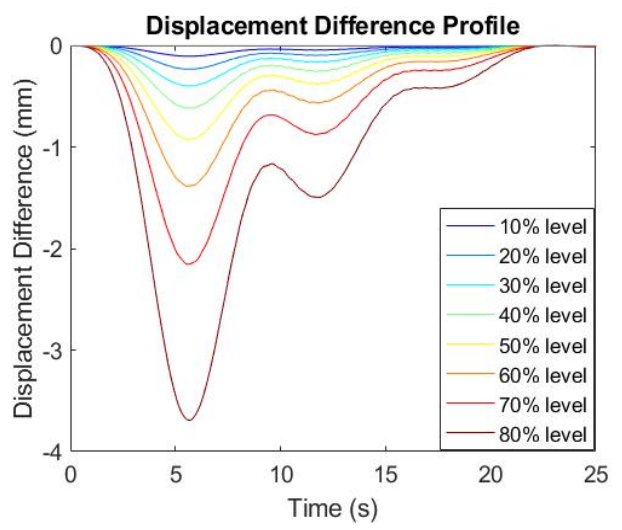

(b)

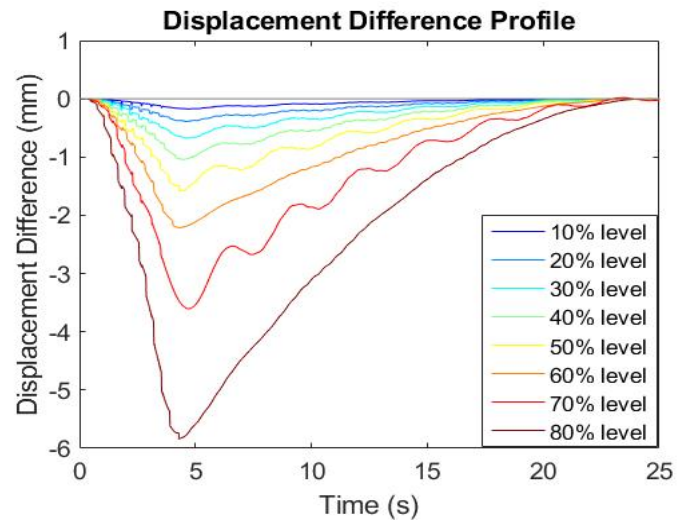

(d)

Figure 3. Displacement Difference Profile (Damaged Element 2, 20\% L) for (a) Vehicle 1, (b) Vehicle 2, (c)Vehicle 3, and (d) Vehicle 4.
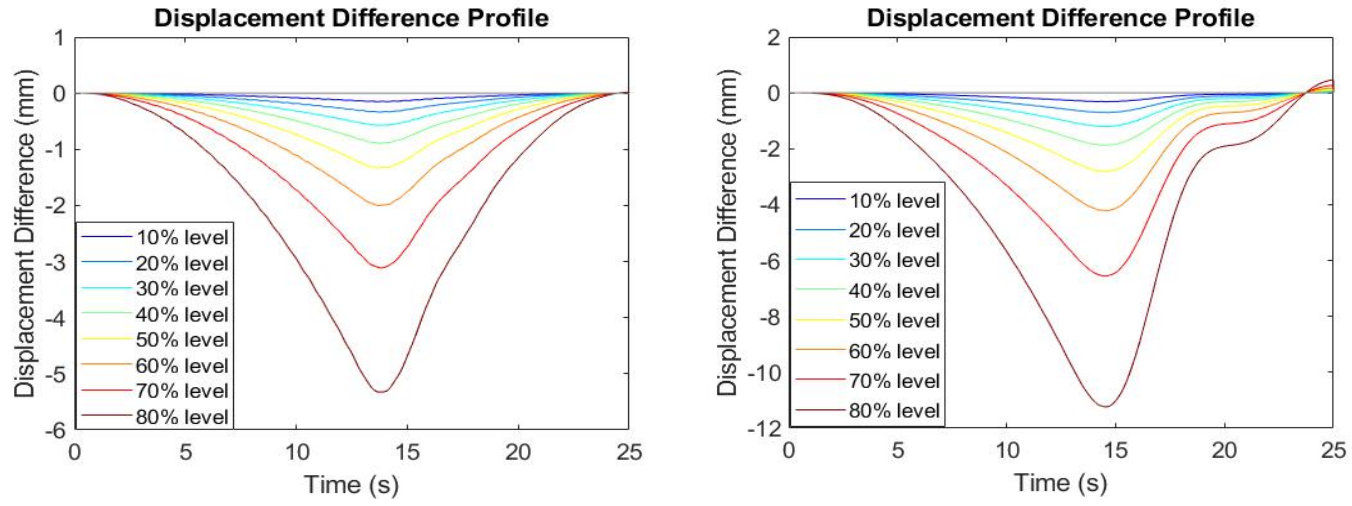

(a)

(b) 


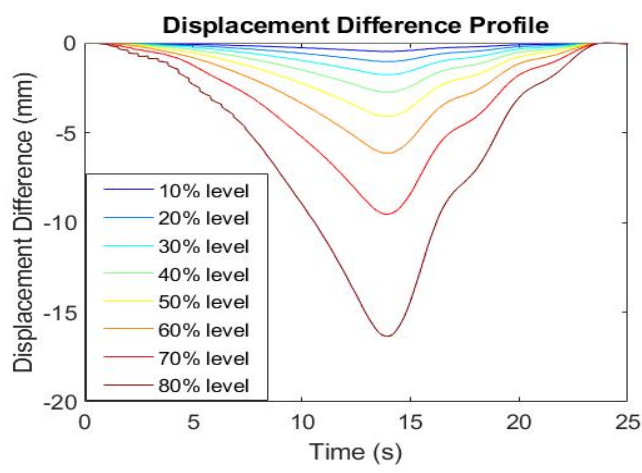

(c)

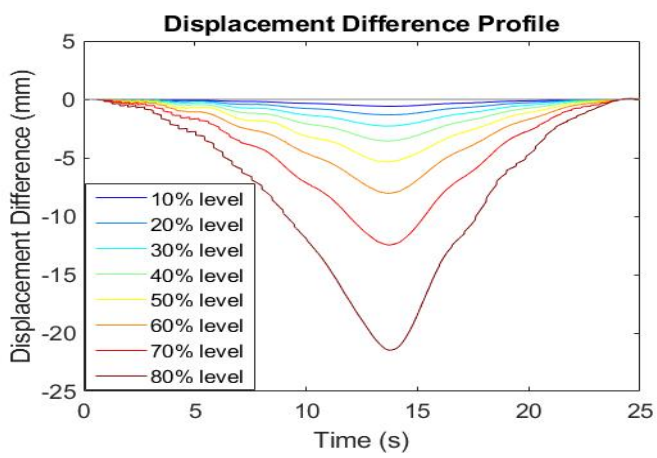

(d)

Figure 4. Displacement Difference Profile (Damaged Element 6, 60\% L) for (a) Vehicle 1, (b) Vehicle 2, (c)Vehicle 3, and (d) Vehicle 4.

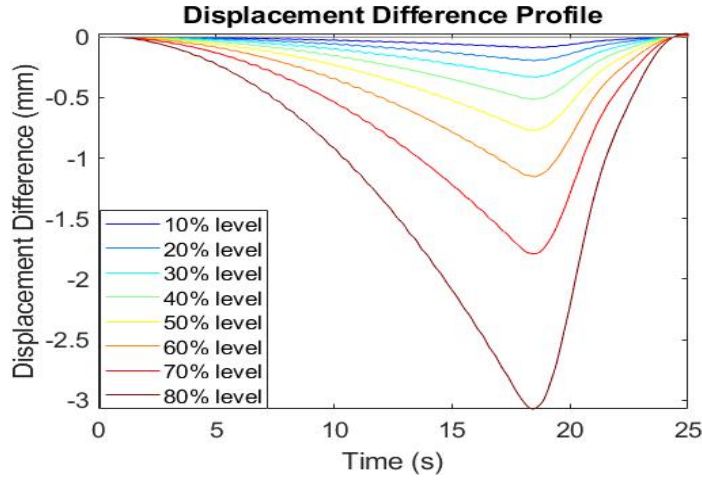

(a)

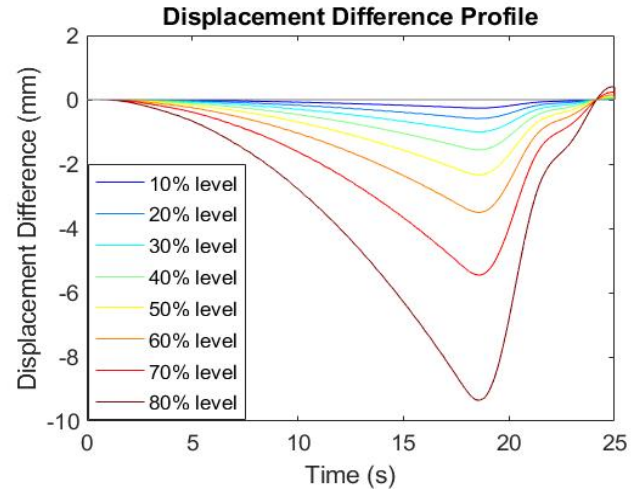

(c)

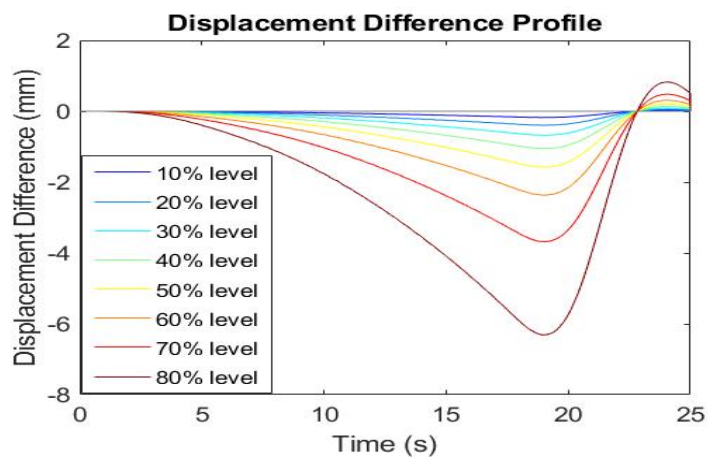

(b)

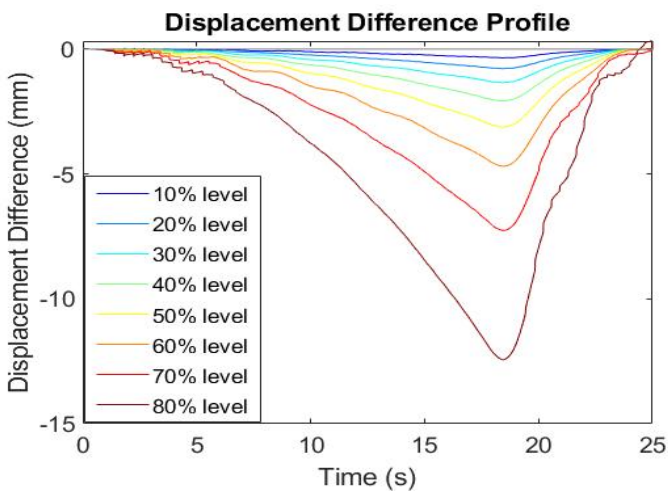

(d)

Figure 5. Displacement Difference Profile (Damaged Element 8, 80\% L) for (a) Vehicle 1, (b) Vehicle 2, (c)Vehicle 3, and (d) Vehicle 4. 


\section{OPTIMIZATION OF THE VEHICLE PARAMETERS}

The main challenges of the drive-by bridge inspection using vehicle deflection profile as damage indicator can be seen in the vehicle displacement measurement and the noise elimination. In reality, the measurement of small displacement of vehicle is challenging, which always requires sensors with high sensitivity. Additionally, the vehicle response could be dominated by the dynamic components of vehicle, masking the damage characteristics (Gonzalez et al. 2008). The parameter optimization of vehicle in this regard is necessary, by which the bridge dynamic changes can be reflected effectively in the vehicle response. The focuses in this section will be on the displacement maximization and the accuracy improvement. The vehicle parameters being assessed are $\mathrm{m}_{\mathrm{v}}$ (vehicle mass), $\mathrm{k}_{\mathrm{v}}$ (vehicle stiffness), and zeta (vehicle damping ratio), which can represent a general car model (Lin and Yang 2005). Each vehicle parameter of interest is independent (would not affect or be affected by other parameters) and reasonably these parameters will be investigated separately.

In the first step, the peaks of vehicle response corresponding to parameter changes will be collected by employing the Monte Carlo Method, which aims to solve deterministic problems utilizing repeated samplings. The value of interest parameter will be changed many times within the range while other 2 vehicle parameters remaining constant to obtain the vehicle responses, by which the corresponding displacement difference profiles of vehicle between healthy and damaged beams can be calculated. Then a diagram illustrating the max displacement differences corresponding to the parameter changes can be drawn through many times of repetition, where the optimum parameter is always considered as the parameter value that provides the peak in the diagram. After that, the steps above will be repeated for each parameter in separate damage scenarios to determine the optimum parameters in terms of vertical displacement measurement. The above procedure will be processed for the damage locations of Damaged Element 2, 6 and 8 with $80 \%$ stiffness reduction separately. Initializing that $\mathrm{v}=15 \mathrm{~m} / \mathrm{s}, \mathrm{m}_{\mathrm{v}}=10000 \mathrm{~kg}$, $\mathrm{k}_{\mathrm{v}}=250000 \mathrm{~N} / \mathrm{m}$ and zeta $=0.05$, the max displacement differences corresponding to vehicle damping ratio (zeta), vehicle stiffness $\left(\mathrm{k}_{\mathrm{v}}\right)$ and vehicle mass $\left(\mathrm{m}_{\mathrm{v}}\right)$ for Damaged Element 2, $6 \& 8$ with $20 \%$ severity are given as shown in Figure $6-8$ respectively.

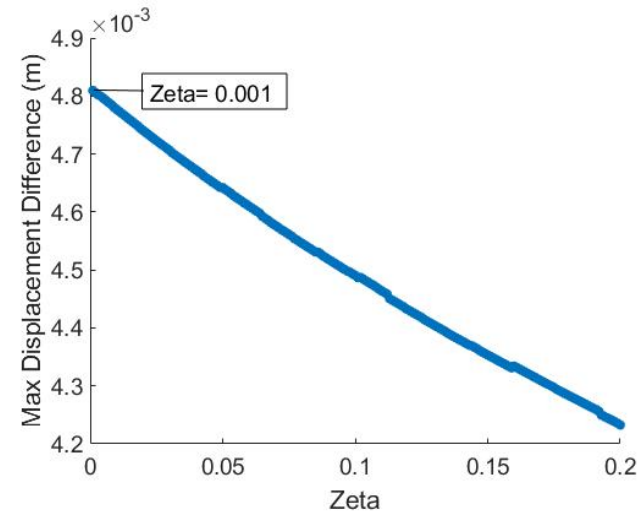

(a)

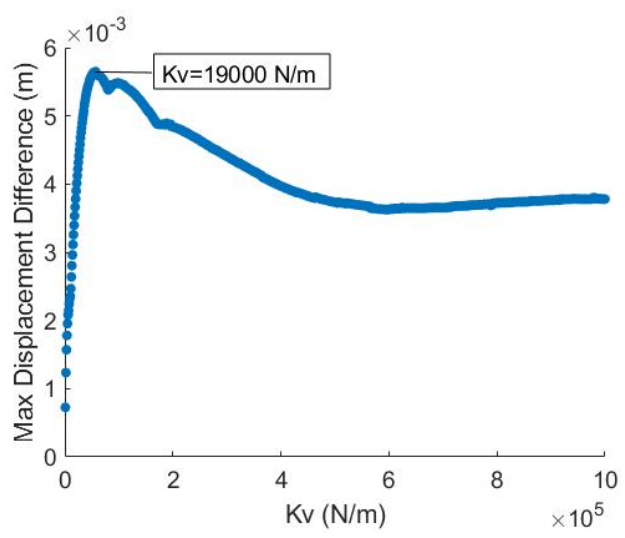

(b) 


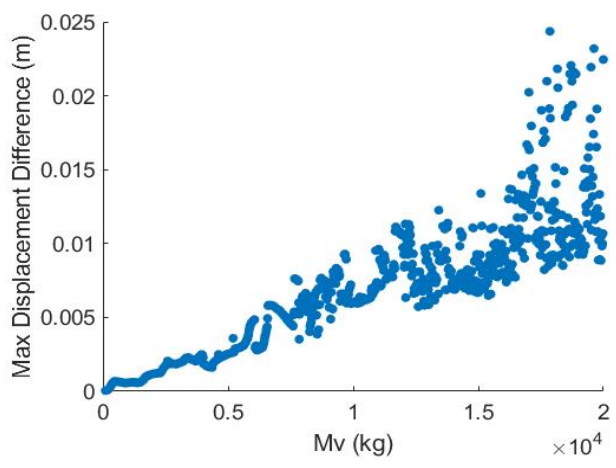

(c)

Figure 6. The max displacement differences for Damaged Element 2 corresponding to (a) Vehicle damping ratio, zeta (b) Vehicle stiffness, $\mathrm{k}_{\mathrm{v}}$ (c) Vehicle mass, $\mathrm{m}_{\mathrm{v}}$.

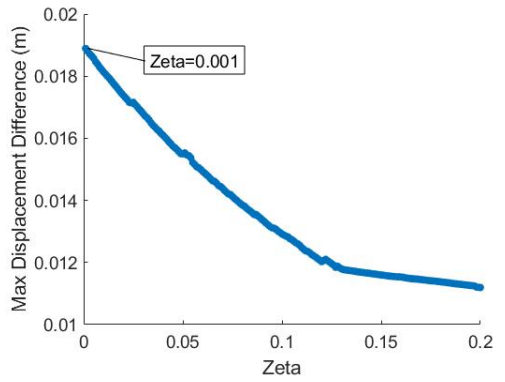

(a)

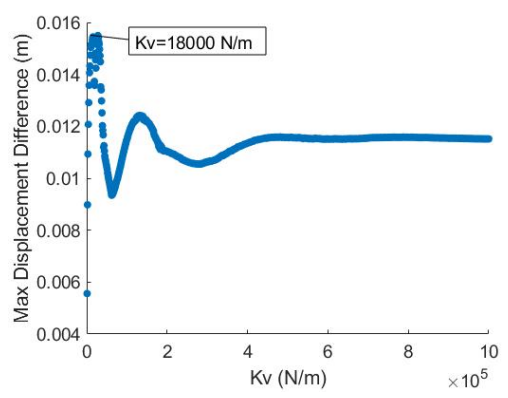

(b)

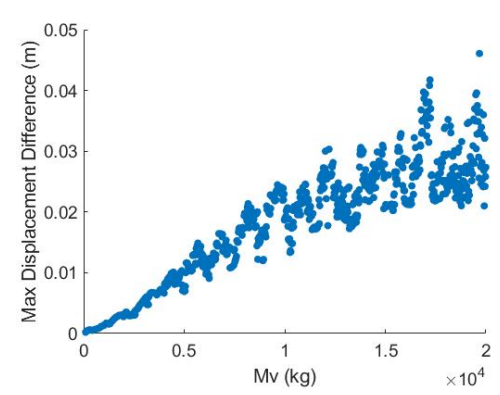

(c)

Figure 7. The max displacement differences for Damaged Element 6 corresponding to (a) Vehicle damping ratio, zeta (b) Vehicle stiffness, $\mathrm{k}_{\mathrm{v}}$ (c) Vehicle mass, $\mathrm{m}_{\mathrm{v}}$.

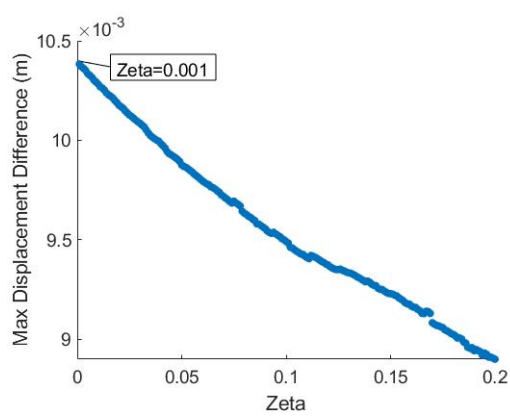

(a)

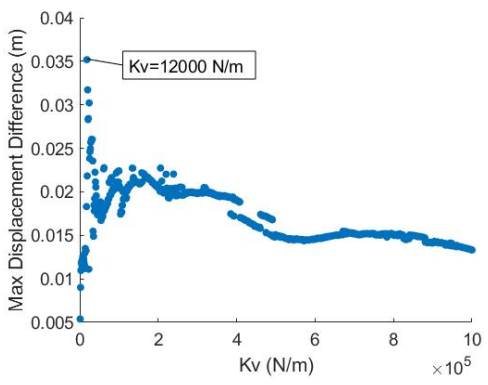

(b)

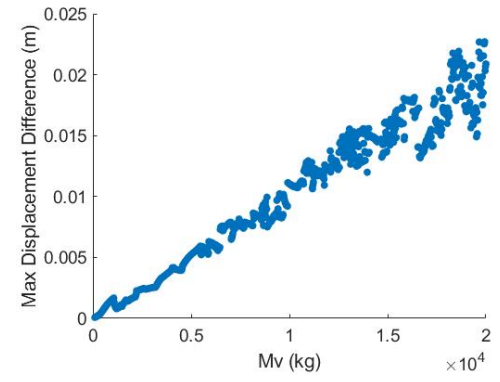

(c)

Figure 8. The max displacement differences for Damaged Element 8 corresponding to (a) Vehicle damping ratio, zeta (b) Vehicle stiffness, $\mathrm{k}_{\mathrm{v}}$ (c) Vehicle mass, $\mathrm{m}_{\mathrm{v}}$. 
As shown in Figures 6-8, similar trends can be witnessed in all damage scenarios. The max displacement difference rises with vehicle mass ignoring some fluctuations and declines as vehicle damping ratio increases. From the correlation between vehicle stiffness and the max displacement difference, observably the max displacement difference rises sharply to the peak before dropping dramatically to the lower point, after which there is a stable trend as the $\mathrm{k}_{\mathrm{v}}$ increasing. It can be seen that vehicle mass $\left(\mathrm{m}_{\mathrm{v}}\right)$ has the most significant impact on the displacement differences among these three parameters, presenting strong linear correlation as shown in Figure 9, the Linear regression for vehicle mass, while the zeta, which is the vehicle damping ratio, presents less significant influence in vehicle responses. The displacement differences reach their extremums only when the $\mathrm{k}_{\mathrm{v}}$ (vehicle stiffness) are selected within specific values, which might be relevant to the resonance (Yang et al. 2004). Thus, generally the heaviest vehicle mass and smallest damping ratio are preferable in order to maximize the displacement measurement, while the optimum vehicle stiffness should be determined depending on the specific damage situations. The optimum parameters obtained from the displacement maximization are given in Table 3.

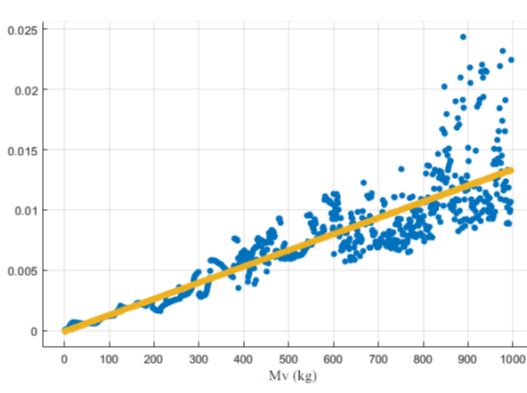

(a)

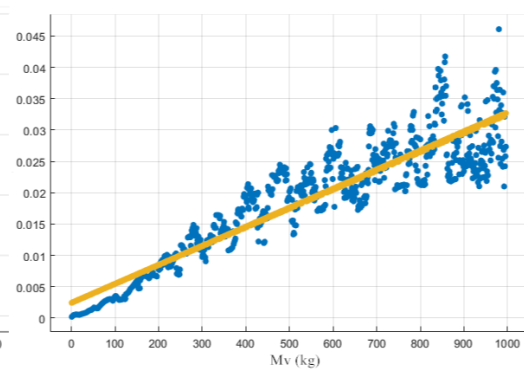

(b)

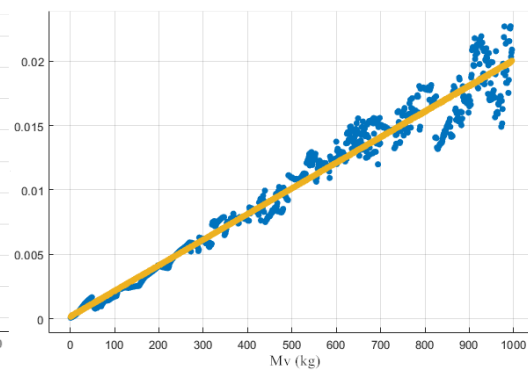

(c)

Figure 9. Linear regression on vehicle mass, $m_{v}$ for (a) Damaged Element 2 (b) Damaged Element 6 (c) Damaged Element 8.

Table 3. The Optimum Parameters for displacement measurement.

\begin{tabular}{|c|c|c|c|}
\hline & $\begin{array}{c}\text { Vehicle Damping } \\
\text { Ratio, zeta }\end{array}$ & $\begin{array}{c}\text { Vehicle Stiffness, } \mathrm{k}_{\mathrm{v}} \\
(\mathrm{N} / \mathrm{m})\end{array}$ & $\begin{array}{c}\text { Vehicle Mass, } \mathrm{m}_{\mathrm{v}} \\
(\mathrm{kg})\end{array}$ \\
\hline $\begin{array}{c}\text { Damaged } \\
\text { Element 2 }\end{array}$ & 0.001 & 19000 & 20000 \\
\hline $\begin{array}{c}\text { Damaged } \\
\text { Element 6 }\end{array}$ & 0.001 & 18000 & 20000 \\
\hline $\begin{array}{c}\text { Damaged } \\
\text { Element 8 }\end{array}$ & 0.001 & 12000 & 20000 \\
\hline
\end{tabular}

The next step is to investigate the parameter effects on vehicle response individually by comparing different parameters. Applying the optimum parameters above for displacement maximization, the displacement difference profiles corresponding to different parameter values can be obtained by varying the interest parameter with the same increasement when other two parameters remain constant. The profiles will be adopted based on the same damage scenarios as above, where damage is included in Elements 2, 6, and 8 with $80 \%$ stiffness reduction. By numerous 
simulations, the vehicle displacement difference profiles corresponding to vehicle damping ratio (zeta), vehicle stiffness $\left(\mathrm{k}_{\mathrm{v}}\right)$ and vehicle mass $\left(\mathrm{m}_{\mathrm{v}}\right)$ for Damaged Element 2, 6 \& 8 with $80 \%$ stiffness loss are given as shown in Figure 10 - 12 separately.

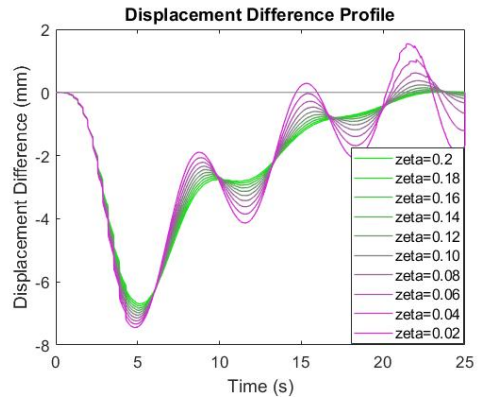

(a)

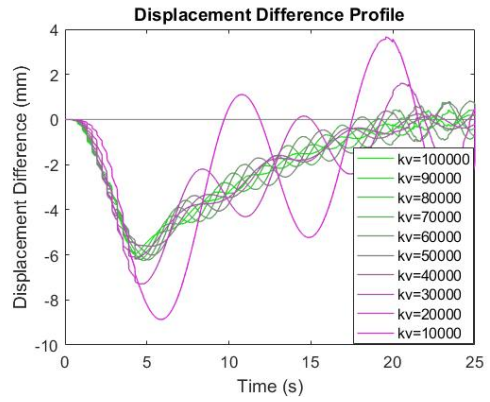

(b)

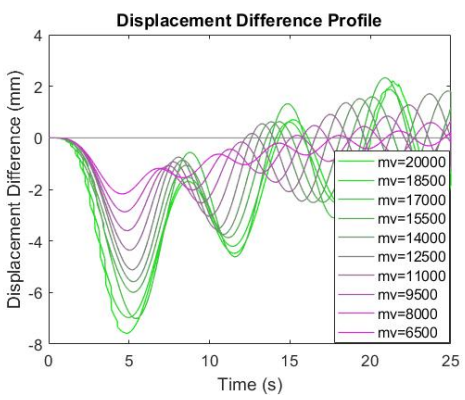

(c)

Figure 10. Vehicle Displacement Difference Profiles (Damaged Element 2, 80\% Stiffness Loss) corresponding to (a) Vehicle damping ratio, zeta (b) Vehicle stiffness, $\mathrm{k}_{\mathrm{v}}$ (c) Vehicle mass, $\mathrm{m}_{\mathrm{v}}$.

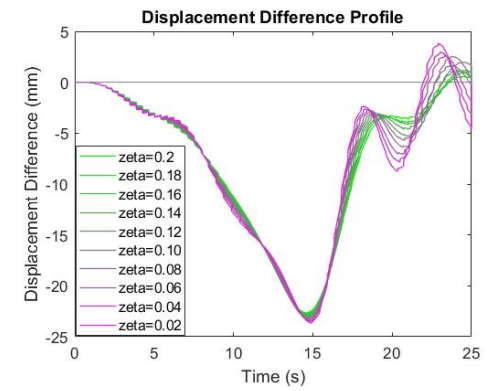

(a)

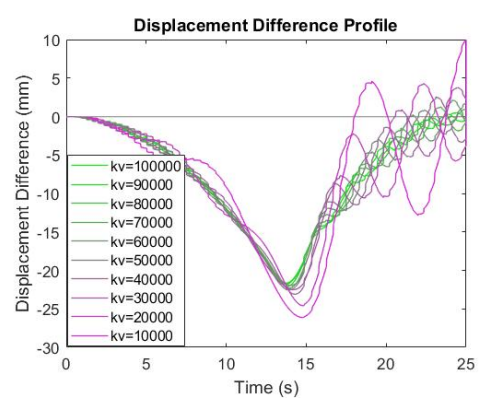

(b)

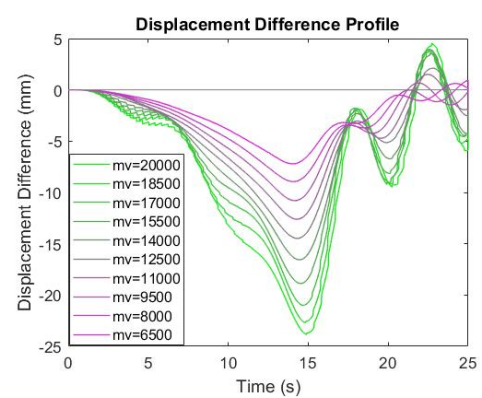

(c)

Figure 11. Vehicle Displacement Difference Profiles (Damaged Element 6, 80\% Stiffness Loss) corresponding to (a) Vehicle damping ratio, zeta (b) Vehicle stiffness, $\mathrm{k}_{\mathrm{v}}$ (c) Vehicle mass, $\mathrm{m}_{\mathrm{v}}$.

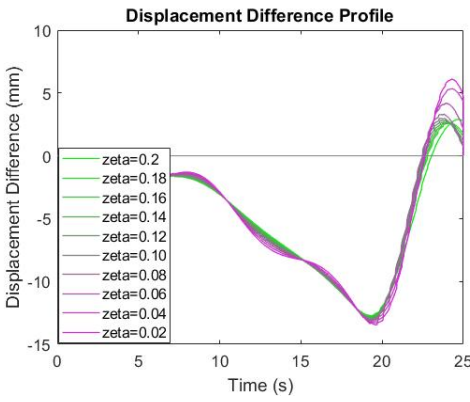

(a)

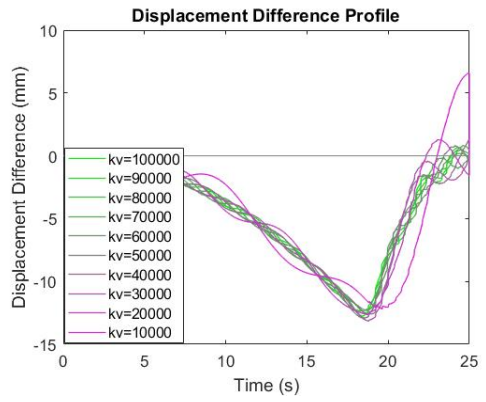

(b)

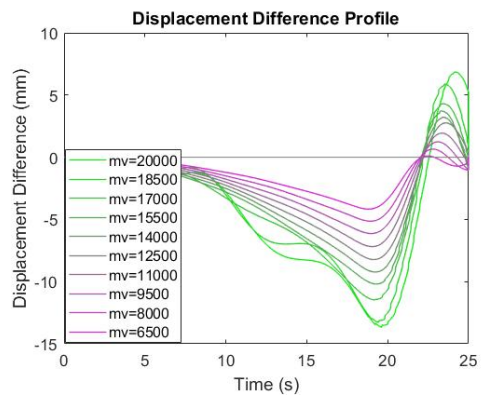

(c)

Figure 12. Vehicle Displacement Difference Profiles (Damaged Element 8, 80\% Stiffness Loss) corresponding to (a) Vehicle damping ratio, zeta (b) Vehicle stiffness, $\mathrm{k}_{\mathrm{v}}$ (c) Vehicle mass, $\mathrm{m}_{\mathrm{v}}$. 
By comparing these results, observably the peaks in profiles of zeta and $\mathrm{m}_{\mathrm{v}}$ can successfully indicate the damage regardless of the parameter changes. In all damage cases, the increase in vehicle mass will lead to nearly linear increment in the magnitude of profile while the vehicle damping ratios could differ the amplitude to a small extent without blurring the peak. The vehicle in Drive-by inspection is employed as not just the signal receiver but also the exciter, and thus stronger vehicle responses could be obtained with heavier vehicle masses (Gonzalez et al. 2008). In practice, heavier vehicles are always desirable as they are less sensitive to the roughness, which minimize the influence of road profile and provide significant results. The damper with damping coefficient of $c_{v}$, presenting the suspension component of vehicles, is an essential part of vehicle configuration, which is employed to connect the vehicle mass in addition to the spring component. The large vehicle damping ratio will weaken the dynamic responses obtained through the VBI and thus reducing the amplitudes in vehicle responses (Kim et al. 2014).

By contrast, it is noticed that the peaks occurred in vehicle displacement difference profiles differ as the vehicle stiffness $\left(\mathrm{k}_{\mathrm{v}}\right)$ changes, which would then result in inaccurate localization of damage. The vehicle mass connects to the road surface via the spring with stiffness coefficient of $\mathrm{k}_{\mathrm{v}}$, presenting the tire components and rear axles. According to the research conducted by Obrien et al. (2014), the greater vehicle stiffness might lead to more significant dynamic axle force resulting in more frequent and small vibrations as shown in the diagrams above. With the increases in vibrations, the peak occurred becomes more difficult to identify and localize. In this study, the optimum vehicle stiffness varies slightly depending on the specific damage cases. This might be relevant to the vehicle-bridge frequency ratio and the resonance phenomenon.

As discussed, the maximization of vehicle displacement and improvement of result accuracy are the key in parameter optimization. It is clear from the above figures that the displacement measurement of vehicle can be considerably increased by adding vehicle mass, which could be the most effective strategy. While the determination of appropriate vehicle stiffness plays a key role in accurate damage localization, depending highly on the specific damage situations. The changes in vehicle damping ratio can differ the amplitudes to some extent but affect the vehicle difference displacement profile less significantly. To accept the better performance of damage inspection, the smaller damping ratio is preferable as it could provide slightly greater displacement difference without interrupting the result accuracy. By the optimization analysis using the Monte Carlo Method, the optimum parameters are designed as shown in Figure 13.

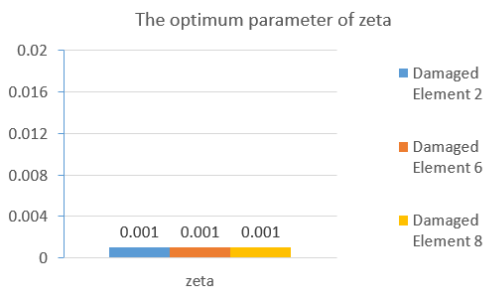

(a)

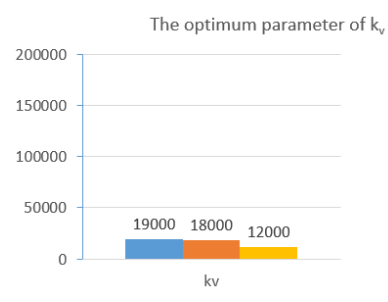

(b)

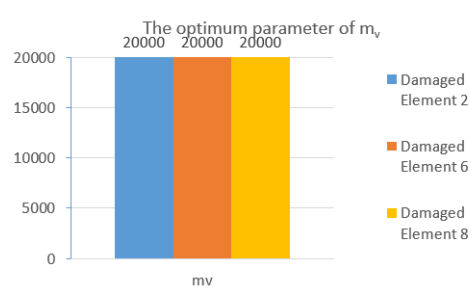

(c)

Figure 13. The Optimum Parameters. 


\section{DAMAGE DETECTION BASED ON THE OPTIMUM PARAMETERS}

In this section, the presented method will be used to test bridge damage with spans of 20, 25 and $30 \mathrm{~m}$, employing the designed parameters. Bridge properties except for the span are identical as shown in Table 1 above. Bridge damage will be involved in element $2(20 \% \mathrm{~L}), 6(60 \% \mathrm{~L})$ and $8(80 \% \mathrm{~L})$ with damage levels increasing from $10 \%$ to $80 \%$ gradually. Other bridge properties such as road roughness are also identical as the above cases. The vehicle profiles below are received here by solving the interaction between bridge and vehicles. Results obtained via vehicle responses are plotted in Figure 14-16 below for bridge spans of 20, 25 and $30 \mathrm{~m}$.

Similarly, for all bridge spans, the peaks in profile can generally indicate the damage location even for small damage levels. While the damage severity is presented as the relative profile difference between two damage levels. Compared with the results from testing vehicles above, bridge damage detection based on the optimum parameters provides higher sensitivity in damage location, and greater vehicle response to damage, in which the severity information can be identified easier. It can also be seen that the vertical displacement profile, which is regarded as damage indicator, is within the millimeter range and it could be easily measured by deflectometers. Obviously, it is feasible to localize and quantify the bridge damage from the vehicle vertical displacement response.

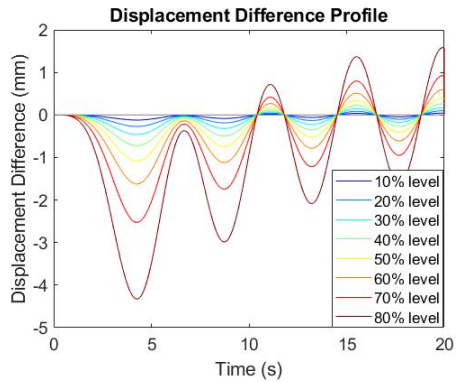

(a)

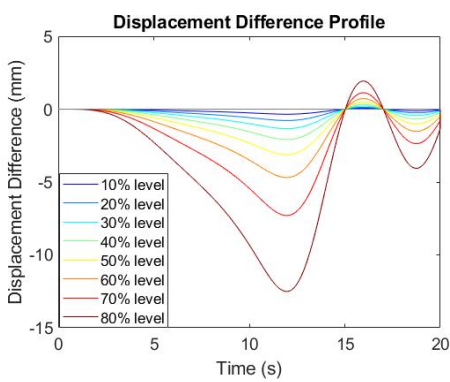

(b)

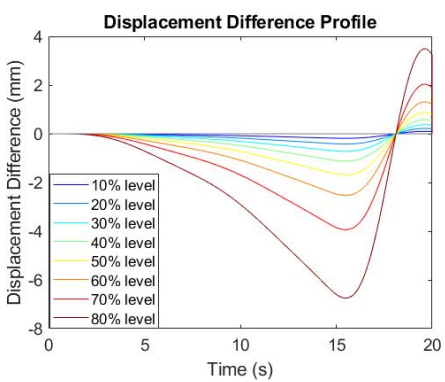

(c)

Figure 14. Vehicle Displacement Difference Profile (20 m span) for (a) Damaged element 2 (20\%L), (b) Damaged element $6(60 \% \mathrm{~L})$, (c) Damaged element 8 (80\%L).

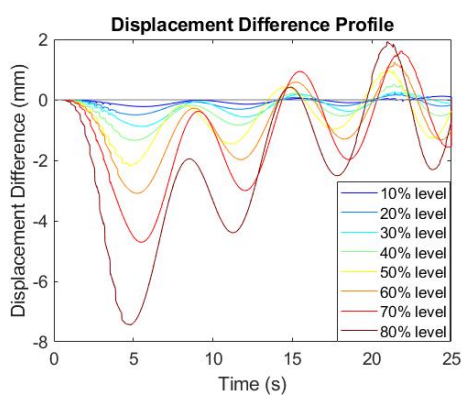

(a)

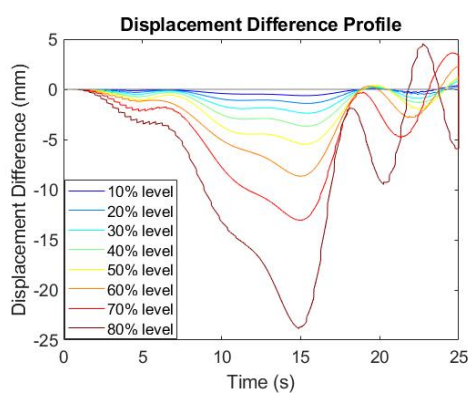

(b)

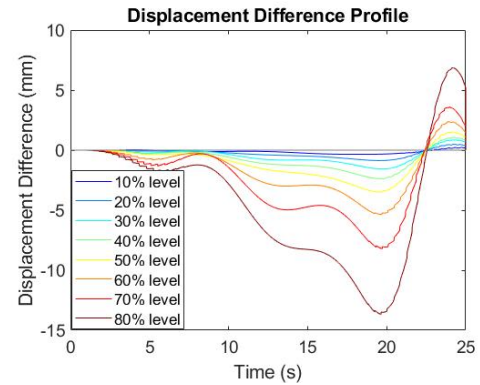

(c)

Figure 15. Vehicle Displacement Difference Profile (25 m span) for (a) Damaged element 2 (20\%L), (b) Damaged element 6 (60\%L), (c) Damaged element 8 (80\%L). 


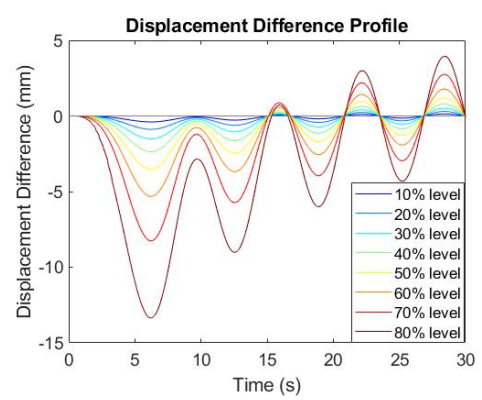

(a)

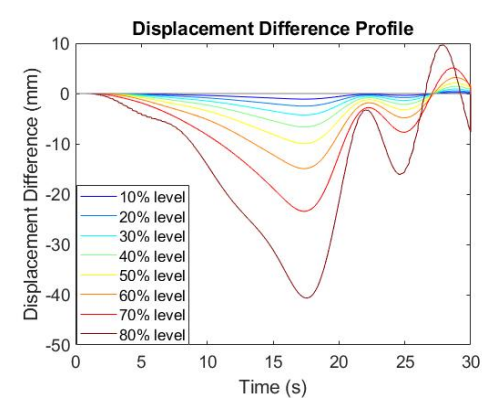

(b)

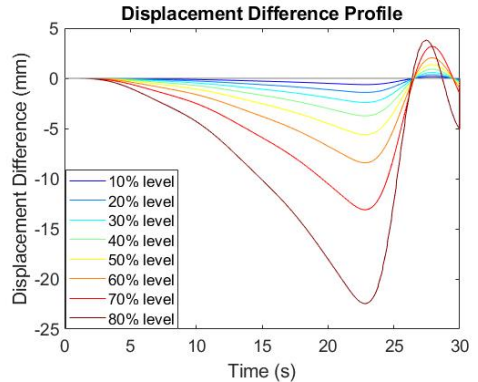

(c)

Figure 16. Vehicle Displacement Difference Profile (30 m span) for (a) Damaged element 2 (20\%L), (b) Damaged element 6 (60\%L), (c) Damaged element $8(80 \% \mathrm{~L})$.

\section{EFFECTIVENESS OF THE PARAMETER OPTIMIZATION}

This part aims to examine the effectiveness of parameter optimization in improving the detection performance, and 10 groups of random vehicle configurations generated in MATLAB will be employed. The vehicle stiffness $\left(\mathrm{k}_{\mathrm{v}}\right)$ varies from $5000 \mathrm{~N} / \mathrm{m}$ to $100000 \mathrm{~N} / \mathrm{m}$ and the vehicle mass $\left(\mathrm{m}_{\mathrm{v}}\right)$ differs between $5000 \mathrm{~kg}$ and $20000 \mathrm{~kg}$. While the reasonable vehicle damping ratio (zeta) ranges from 0.001 to 0.2 . The random vehicle configurations generated as shown in Table 4 will be used as inputs to calculate the profiles for all 3 damage scenarios above. Figure 17 shows that comparing the profiles of the optimum and that of random cases, the designed parameters can provide more significant vehicle response and higher result accuracy in bridge damage detection and localization.

Table 4. Random Vehicle Parameters.

\begin{tabular}{|c|c|c|c|}
\hline & zeta & $\mathrm{k}_{\mathrm{v}}(\mathrm{N} / \mathrm{m})$ & $\mathrm{m}_{\mathrm{v}}(\mathrm{kg})$ \\
\hline Random 1 & 0.006 & 92733 & 17202 \\
\hline Random 2 & 0.189 & 73271 & 13105 \\
\hline Random 3 & 0.103 & 71509 & 19447 \\
\hline Random 4 & 0.091 & 34088 & 6307 \\
\hline Random 5 & 0.129 & 75865 & 11312 \\
\hline Random 6 & 0.141 & 42790 & 18076 \\
\hline Random 7 & 0.158 & 79233 & 8122 \\
\hline Random 8 & 0.180 & 36300 & 8462 \\
\hline Random 9 & 0.002 & 49551 & 15580 \\
\hline Random 10 & 0.112 & 90518 & \\
\hline
\end{tabular}




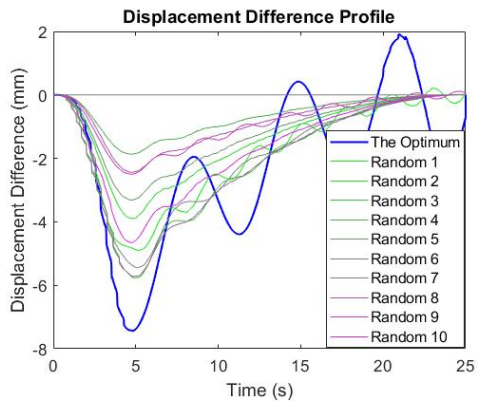

(a)

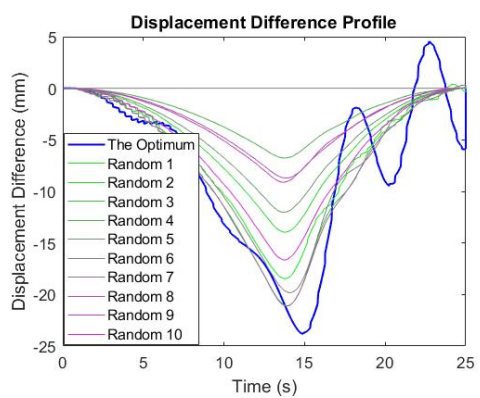

(b)

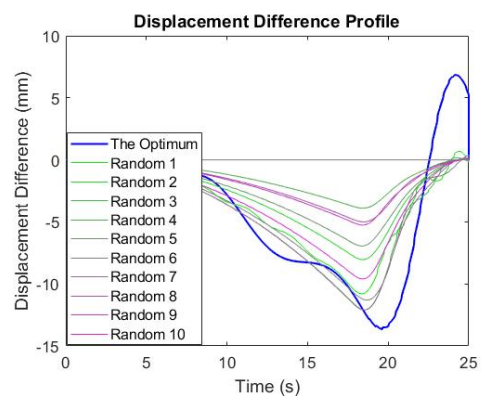

(c)

Figure 17. Displacement Difference Profiles for random vehicle configurations: (a) Damaged element 2, 80\% Stiffness Loss (b) Damaged element 6, 80\% Stiffness Loss (c) Damaged element 8, 80\% Stiffness Loss.

\section{CONCLUSION AND DISCUSSION}

This paper proposes a new method of Drive-by inspection with parameter optimization employing vertical vehicle displacement profile as damage indicator. The vehicle system with diverse configurations is used to excite the bridge, which in turn is excited by the bridge and serves as receiver of the vehicle vibrations. The vehicle time history is received here employing a VBI model, and by subtracting the vehicle time histories between the healthy beam and that of damaged cases, the displacement difference profiles can be obtained. It is found that the peak in profile can roughly indicate the damage location while the damage severity is presented as the increment in profile difference though tests of the 4 vehicle configurations. It can be also seen in the results that vehicle parameters such as $\mathrm{m}_{\mathrm{v}}$ (vehicle mass), $\mathrm{k}_{\mathrm{v}}$ (vehicle stiffness), and $\mathrm{c}_{\mathrm{v}}$ (vehicle damping) will considerably affect the detection performance. Extracting damage information from small vehicle displacement response would be difficult and inappropriate vehicle configurations might mask the damage characteristics. In order to clearly identify the damage information and enhance the result accuracy, this study optimizes the major vehicle parameters using the Monte Carlo Methods and analyses their influences briefly.

Based on the numerical studies, it is confirmed that the vehicle displacement response is sensitive to parameter of vehicle mass, presenting strong linear correlation. While designing the appropriate vehicle stiffness is the key to improving result accuracy, where greater stiffness will lead to more frequent and small vibrations and blurs the peaks in profile. Generally, vehicles with greater mass, smaller and proper stiffness would be preferable for vehicledisplacement based Drive-by bridge inspection method. The small vehicle damping ratio is also recommended but its influence is less significant than other two parameters. Applying the designed parameters, test results show that the application of proposed method can effectively detect and localize the damage for bridge spans of 20, 25 and 30 $m$ under diverse damage scenarios. The effectiveness of parameter optimization in improving the result performance has also been examined though the random configuration test.

For application of the proposed approach to practical problems, there are several suggestions: (1) The vehicle properties should be identified and designed properly before the tasks. (2) The low vehicle speed is suggested for receiving high resolution of vehicle displacement profile. (3) Three or more runs of tests with different vehicle configurations are suggested in order to reduce the random errors and bias due to impacts of vehicle parameter difference. 
The presented method shows efficiency, simplicity and robustness for bridge health monitoring. The damage indicator, vehicle vertical displacement profile, also has high recognizability for computer programs (easily identified by computer programs) and hopefully it can be used as indicator for data-driven analytics methods. With the techniques of deflectometer and computer science developing rapidly these days, predictably the Drive-by bridge monitoring using vertical vehicle displacement as damage indicator will become increasingly popular and will contribute to the wide application of the Drive-by bridge inspection based on vehicle response in general. In order to allow this method to be implemented to the field application, field test calibrations including the environmental effects and other uncertainties are required. Further studies will be conducted to filter out environmental noises and test its applicability in different bridge types.

\section{REFERENCES}

Malekjafarian, A., McGetrick, P. \& O'Brien, E. 2015. A Review of Indirect Bridge Monitoring Using Passing Vehicles. Shock and Vibration 2025: 1-16.

Sohn, H., Farrar, C.R., Hemez, F.M., Shunk, D.D., Stinemates, D.W., Nadler, B.R. \& Czarnecki, J.J. 2003. A review of structural health monitoring literature: 1996-2001. Los Alamos National Laboratory, USA.

Enckell, M., Glisic, B., Myrvoll, F. \& Bergstrand, B. 2011. Evaluation of a large-scale bridge strain, temperature and crack monitoring with distributed fibre optic sensors. Journal of Civil Structural Health Monitoring 1(2): $37-46$.

Yang, Y., Lin, C. \& Yau, J. 2004. Extracting bridge frequencies from the dynamic response of a passing vehicle. Journal of Sound and Vibration 272(3-5): 471-493.

Yang, Y. \& Lin, C. 2005. Vehicle-bridge interaction dynamics and potential applications. Journal of Sound and Vibration 284 (1-2): 205-226.

Kim, C.W. \& Kawatani, M. 2009. Challenge for a drive-by bridge inspection in International Conference, 10th, Structural safety and reliability; Safety, reliability and risk of structures, infrastructures and engineering systems; ICOSSAR2009; Osaka, Japan.

McGetrick, P.J., Gonzlez, A. \& Obrien, E.J. 2009. Theoretical investigation of the use of a moving vehicle to identify bridge dynamic parameters. Insight - Non-Destructive Testing and Condition Monitoring 51(8): 433438 .

Keenahan, J., Obrien, E.J., McGetrick, P.J. \& Gonzalez, A. 2014. The use of a dynamic truck-trailer drive-by system to monitor bridge damping. Structural Health Monitoring 13(2): 143-157.

Zhang, Y., Wang, L. \& Xiang, Z. 2012. Damage detection by mode shape squares extracted from a passing vehicle. Journal of Sound and Vibration 331(2): 291-307.

Yang, Y., Li, Y. \& Chang, K. 2014. Constructing the mode shapes of a bridge from a passing vehicle: a theoretical study. SMART STRUCTURES AND SYSTEMS 13(5): 797-819.

Malekjafarian, A. \& Obrien, E.J. 2014. Identification of bridge mode shapes using short time frequency domain decomposition of the responses measured in a passing vehicle. Engineering Structures 81:386-397.

Miyamoto, A. \& Yabe, A. 2012. Development of practical health monitoring system for short-and medium-span bridges based on vibration responses of city bus. Journal of Civil Structural Health Monitoring 2(1): 47-63.

Obrien, E.J. \& Keenahan, J. 2015. Drive-by damage detection in bridges using the apparent profile. Structural Control and Health Monitoring 22(5): 813-825.

De Boer, P.T., Kroese, D., Mannor, S. \& Rubinstein, R. 2005. A Tutorial on the Cross-Entropy Method. Annals of Operations Research 134(1): 19-67. 
Yin, S.H. \& Tang, C.Y. 2011. Identifying Cable Tension Loss and Deck Damage in a Cable-Stayed Bridge Using a Moving Vehicle. Journal of Vibration and Acoustics 133(2)/ 021007.

Hester, D. \& González, A. 2016. A discussion on the merits and limitations of using drive-by monitoring to detect localised damage in a bridge. Mechanical Systems and Signal Processing: 234-253.

McGetrick, P.J. \& Kim, C.W. 2013. A Parametric Study of a Drive by Bridge Inspection System Based on the Morlet Wavelet. Key Engineering Materials: 569-570 \& 262-269.

Briggs, R.C., Johnson, R.F., Stubstad, R.N. \& Pierce, L. 2000. A comparison of the rolling weight deflectometer with the falling weight deflectometer in Symposium on Nondestructive Testing of Pavements and Backcalculation of Moduli 3: 444-456. West Conshohocken, PA, USA.

ISO 8608 1995. Mechanical vibration-road surface profiles-reporting of measured data. Geneva.

González, A. 2010. Vehicle-bridge dynamic interaction using finite element modelling. In D. Moratal, ed. Finite Element Analysis. Sciyo: 637-662.

Clough, R.W. \& Penzien, J. 1975. Dynamics of structures. New York, NY. USA: McGraw-Hill.

Cebon, D. 1999. Handbook of vehicle-road interaction. Swets and Zeitlinger Publishers, Lisse. The Netherlands.

Sinha, J.K., Friswell, M.I. \& Edwards, S. 2002. Simplified models for the location of cracks in beam structures using measured vibration data. Journal of Sound and Vibration 251(1): 13-38.

Gonzalez, A., Rattigan, P., O'Brien, E. \& Caprani, C.C. 2008. Determination of bridge lifetime dynamic amplification factor using finite element analysis of critical loading scenarios. Engineering Structures 30(9): $2330-2337$.

Kim, C.W., Isemoto, R., McGetrick, P.J., Kawatani, M. \& Obrien, E.J. 2014. Drive-by bridge inspection from three different approaches. Smart Structures and Systems 13(5): 775-796.

Obrien, E.J., McGetrick, P.J. \& Gonzalez, A. 2014. A drive-by inspection system via vehicle moving force identification. Smart Structures and Systems 13(5): 821-848. 